\title{
Promoting Sustainable Urban Neighborhood towards Walkability
}

\author{
Diyanah Inani Azmi, Hafazah Abdul Karim \\ Faculty of Architecture, Planning \& Surveying, \\ Universiti Teknologi MARA, Malaysia \\ diyanah_inani@yahoo.com
}

\begin{abstract}
Climate change is a widely accepted fact. Urbanization and industrialization are the main cause of the climate change phenomena all around the world. One of the main problems of urbanization is the increase in growing dependence on automobiles. The main modes of transportation even in the neighborhood area are the private cars because it is the norm of urbanites to use the motorized vehicles rather than to walk. This shows that the planning and design of the neighborhood itself can influence the walkability of the housing area. This paper highlights the implication of walkability towards promoting sustainable urban neighborhood.
\end{abstract}

Keywords: Walkability; climate change; neighborhood design; community facilities; sustainable

eISSN 2514-751X @ 2018. The Authors. Published for AMER ABRA cE-Bs by e-International Publishing House, Ltd., UK. This is an open-access article under the CC BY-NC-ND license (http://creativecommons.org/licenses/bync-nd/4.0/). Peer-review under responsibility of AMER (Association of Malaysian Environment-Behaviour Researchers), ABRA (Association of Behavioural Researchers on Asians) and CE-Bs (Centre for EnvironmentBehaviour Studies), Faculty of Architecture, Planning \& Surveying, Universiti Teknologi MARA, Malaysia.

https://doi.org/10.21834/aje-bs.v3i8.290 


\subsection{Introduction}

Neighborhood Concept was first introduced by Clarence Perry in 1910 to solve the problem of transportation in most of the urban centres and housing area. His concept evolved from Ebenezer Howard Garden City theory and social reformed aimed at growing urban population. The Neighborhood Concept proposed by Clarence Perry also took into account the accessibility of residents from their homes to elementary schools and community centred. According to Ratcliff(1975), Clarence Perry stated, "the neighborhood unit is described as a scheme of arrangement for the family life community", where the neighborhood unit is the area for residents getting a convenient access to the community facilities such as an elementary school, adequate common plays spaces, retail shop and facilities. However, in this era of modernization the climate change effect the walkability pattern of neighborhood area especially in equatorial country such as Malaysia. According to United Nation survey, by 2050 nearly 70 percent of the global population will be living in the cities. According to Neal (2003), as urbanization rate increase, there is a pressing need to improve community living in today's neighborhoods as "neighborhood is seen as the most important urban element that establishes the social and economic sustainability of the area, providing the community ties which hold it together...". Effort to improve neighborhood living in today's urban community must be taken seriously because the social values in the urban area are characteristically different from the rural community (Yahya Ibrahim,1995)

Moreover, one of the main problems of urbanization is the increase in growing dependence on automobiles. The main mode of transportation even in the neighborhood area is the private cars because it is the norm of urbanites to use the motorized vehicles rather than to walk. This also leads to the sprawling development and unsustainable lifestyle which disconnect pedestrians to the neighborhood cores by creating housing that sprawled outside of the residence walking zone (Kevin MacNally, 2010). Thus, people realized that there must be sustainable approaches to encounter the climate change phenomena. One of the initiatives is to design a neighborhood area towards a walkability living because the design of the neighborhood can influence the walkability of the housing area. The walkability of the neighborhood can be measured by identifying the walking behaviour of the residents to community facilities provided. Different categories of residents have different types of walking behaviour. Increasing the walkability of the neighborhood means that the planning and design needs to be improved towards more sustainable living.

\subsection{Literature Review}

\subsection{Neighborhood Unit Concept}

The concept of neighborhood unit evolved from the unplanned housing design to the industrial revolution. De Chiara et al (1984)defined neighborhood as, "A residential area with homogeneous characteristics, of a size comparable to that usually served by an elementary school. A typical ideal neighborhood would bean area $3 / 4$ to 1 mile square and containing 6000 to 8000 people". The Neighborhood Unit by Clarence Perry illustrating the relationships between 
the residential components of a neighborhood and nonresidential componentareaby walking distance.Perry's intentions were calibrated to the human foot, not the automobile.

\subsection{Malaysia Neighborhood Unit}

According to Ghazali et al (2011), many countries like Malaysia have adopted the recommendation put forward by Clarence Perry in designing the housing layout. Previous studies by (Qureshi and Siong, 2011) revealed that all residential areas within Putrajaya are developed on the 'neighborhood' concept introduced by Clarence Perry. However, the adaptation of neighborhood concept by Clarence Perry in equatorial country such as Malaysia fails to encourage the community to walk even within their neighborhood. As a result, community today still depends on the automobiles as the main mode of transportation to travel from home to their basic community facilities such as school, local shop and playground.

Malaysia is still struggling to produce the best designing guideline for community facilities planning towards a sustainable environment. According to Azmi \& Karim (2011), the strategic location of community facilities is different depending on the type of community facilities provided. The location of school and playground is prefer to be located at the centred in low cost housing. Local shop should be scattered in different locations with small scale planning to reduce the walking distance. This shows that community facilities planning influence the walkability of people in the neighborhood area.

\subsection{Walkability in Neighborhood}

Many communities today are suffering from a growing dependence on automobiles as the main mode of transportation which results in low- density development and sprawling development patterns. According to Abley (2005), walkability can be defined as "the extent to which the built environment is friendly to the presence of people living, shopping, visiting, enjoying or spending time in an area". According to Franks (2006), walkability is also dependent on human behaviour of the residents in the neighborhood area.

According to Olson (2010), the neighborhood concept by Clarence Perry utilized the five minute walk because Perry was very concerned about the walkability from a residential area to and from school. The five minute walk is a standard describing the average distance that a pedestrian is willing to walk before choosing to drive. However, according to Azmi and Karim (2011) in Malaysia people will only be willing to walk in minimum distance of less than 200 meter before choosing to drive. The argument are the Clarence Perry walking distance standards which is 400 meter is not suitable to be used in equatorial climate such as Malaysia.

\subsection{Sustainable Neighborhood Design Principle}

Sustainability is an approach that all country around the world used today whether in terms of economic, social or environmental. Sustainability is the approach to combat the issues of urbanization especially in the urban area. According to the United Nations (1987), sustainable 
development can be defined as "development that meets the needs of the present without compromising the ability of future generations to meet their own needs." According to Barton etal. (2003), the sustainable urban neighborhood design consists of six principles which are the stakeholder involvement, increase local autonomy, connectivity, diversity, response to place and adaptability.

In this research paper, only three principles are going to be used to testify whether sustainable principle can be adapted in relation to neighborhood design and walkability of neighborhood area. The three principles are;

1) Increase of local autonomy.

The principle of increasing the degree to which localities provided, services and activities should be managed at the lowest feasible level. The neighborhood provides the appropriate level for school, playground and local shop in terms of catchment area radius and strategic location.

2) Diversity.

The principle of diversity is in response to the failure of conformity. The tendency has to segregate uses to safeguard environmental quality such as diversity of modes of movement (choice) such as safety and convenience.

3) Respondent to place.

The ecosystem approach requires recognition of, response to and the heritage of each locality such as climate condition and landscaping.

\subsection{Methodology}

This paper are aim to gather feedbacks and opinions from professionals on how the neighborhood concept used in the urban area affect the walkability in within the neighborhood area using exploratory research approach. This paper is a pilot study of an on-going master research to identify a suitable variable that can be used in the study. The urban neighborhood area chooses are located within Klang Valley such as Shah Alam and Putrajaya. This is a qualitative research approach; the findings of this paper are gathered from interview method. The type of interview used is known as semi-structured interview. According to Laforest (2009), semi-structured interview is hard to determine the exact number of interviews that have to be done for a safety diagnosis, it is important to cover all topics with a range of sources. Semi-structured face to face interview were conducted with 6 experts from the related field such as town planning, architect and landscape architect.

The respondents also are divided into two categories, which are academician and practitioner from the industry. The duration of the interview lasted about 30 to 45 minute and by making an early appointment with the respondents. The interviews are also conducted using a tape recorder. The respondents audio is transcribed using the software called Computer Aided Qualitative Data Analysis (CAQDAS), Nvivo. The analysis technique to analyse the data is known as coding queries technique in Nvivo software. The processes of coding queries techniques are conducted by identify all nodes related to this study. In this case, the main nodes used are neighborhood design, neighborhood walkability and adaptability of 
sustainable principle in relation to neighborhood design and walkability.

\subsection{Result And Discussion}

The findings consist of negative and positive perceptions among the expertise. The following sections will highlight the research findings of this paper in two different forms.

Table 1 shows the coding frequency of respondents' perceptions on walkability and sustainability of urban neighborhood area in Putrajaya and Shah Alam. The coding frequency is gathers by analyses the transcribing of all the respondents using Nvivo analysis techniques. The number shows how often respondents express their negative and positive perception on all the three main characteristics. From the findings (Tab. 1.), shows the majority of respondents give higher negative perceptions rather than the positive perceptions, with the frequency of 38 for negative perceptions and only 11 for positive perceptions. This argues that urban neighborhood in Putrajaya and Shah Alam are still lacking in promoting a walkability environment and sustainable living.

On the other hand, the highest frequency on negatives perceptions by the respondents fall under the characteristics of adopted the sustainable principle in relation to neighborhood design and walkability which are the local autonomy principle. The local autonomy principle consists of questions on does people feel safe to walk and convenient to walk within their neighborhood area. It shows that experts think most of the residents in Putrajaya and Shah Alam do not feel convenience to walk within their neighborhood area. The highest frequency on positives perceptions by respondents fall under the characteristics of neighborhood walkability which are 'easy accessible location of community facilities by walking in the neighborhood'. Playground is chosen as the most accessible community

Figure 1 shows a summary of all perceptions gathered from the respondents. It shows in detail every perception and are divided using the same three main characteristic groupings used in the previous findings of coding frequency table. Based on the findings, urban neighborhood designs in Putrajaya and Shah Alam are found to discourage people to walk. Neighborhood designs in Putrajaya and Shah Alam have poor pedestrian design because they have too many barriers along the way which affect people desire to walk. One of the respondents said that; "Malaysians are not willing to walk because there is too much barrier, we should design toward what I call it barrier free".

In terms of walkability in the neighborhood, people in the urban area especially in Putrajaya and Shah Alam are not willing to walk in reaching community facilities provided in their neighborhood. They are more likely to drive rather than to walk. Perceptions on walking in the neighborhood to three basic community facilities such as school, playground and local shop were gathered. According to respondent's perception on accessibility, only the playgrounds are easily accessible to them compared to the school and the local shops. In terms of walking distance, most of the respondents agreed that they are willing to walk 5 to 10 minute in reaching the community facilities provided in their neighborhood area. Other than that, majority of respondents suggest that the reasons why Malaysian people are not willing to 
walk are because neighborhood design is not well planned in term of community facilities planning. They also think that Malaysians people do not like to walk and carry out healthy activities.

Table 1: Coding Frequency of Respondents Perception on Walkability and Sustainability of Urban Neighborhood Area in Putrajaya and Shah Alam

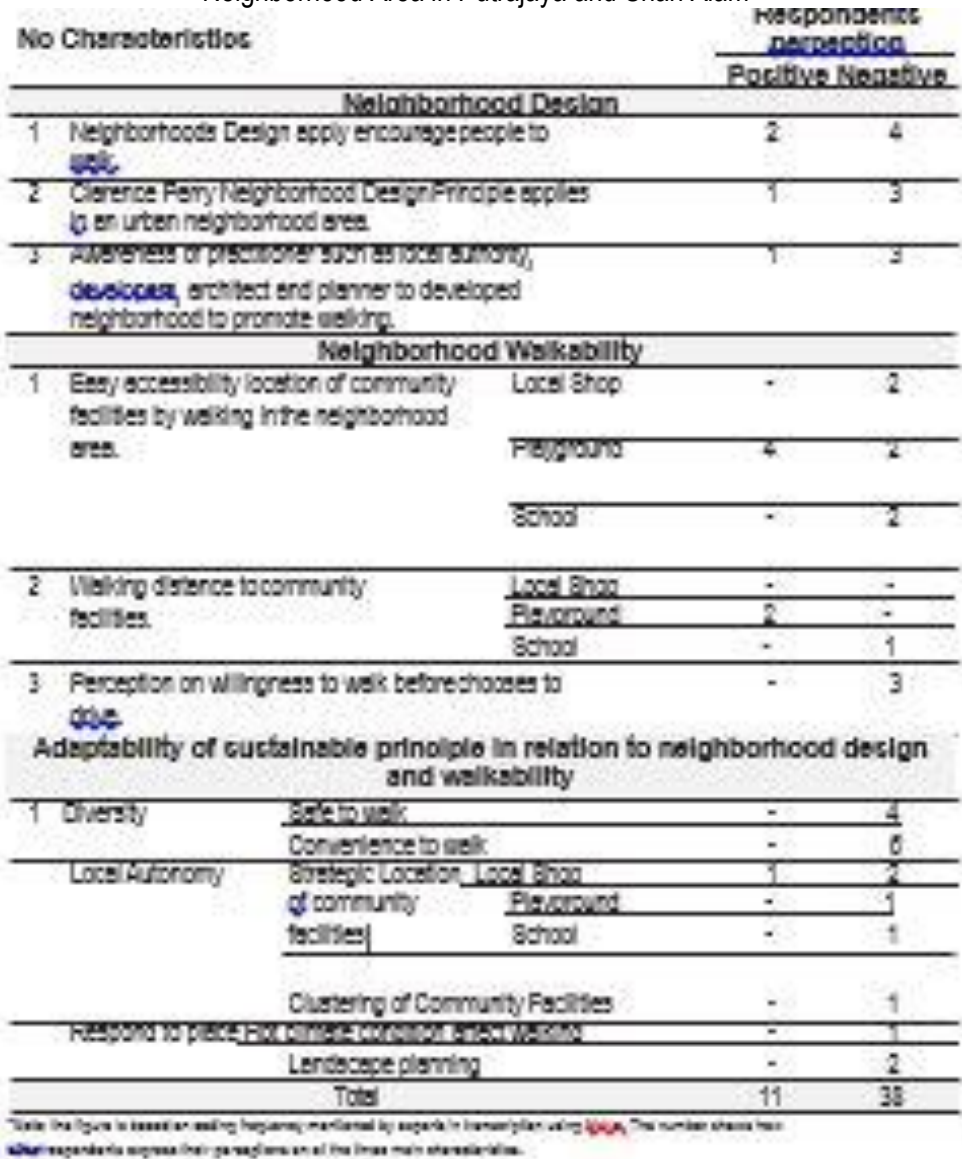

For community facilities planning in Putrajaya, the community facilities do not have proper connectivity from one place to another place even though there are beautiful green networks. Interm of strategic location, neighborhoods in Putrajaya lack of community facilities such as the local shop. Moreover, most of the school locations in Shah Alam and Putrajaya are located near the main road, and this resulted in an unsafe environment to the school children. Safety is also one of the reasons why people are not willing to reach their community facilities by walking. Based on the perceptions of respondents in terms of safety, the reason 
why the urban neighborhoods in Putrajaya and Shah Alam discourage walking is because the road curb provided is too high for walking. There are also lacked of people control the traffic especially near the school area. The respondents also view that a high number of crime and feeling insecure are the reasons why they prefer to drive rather that walk.

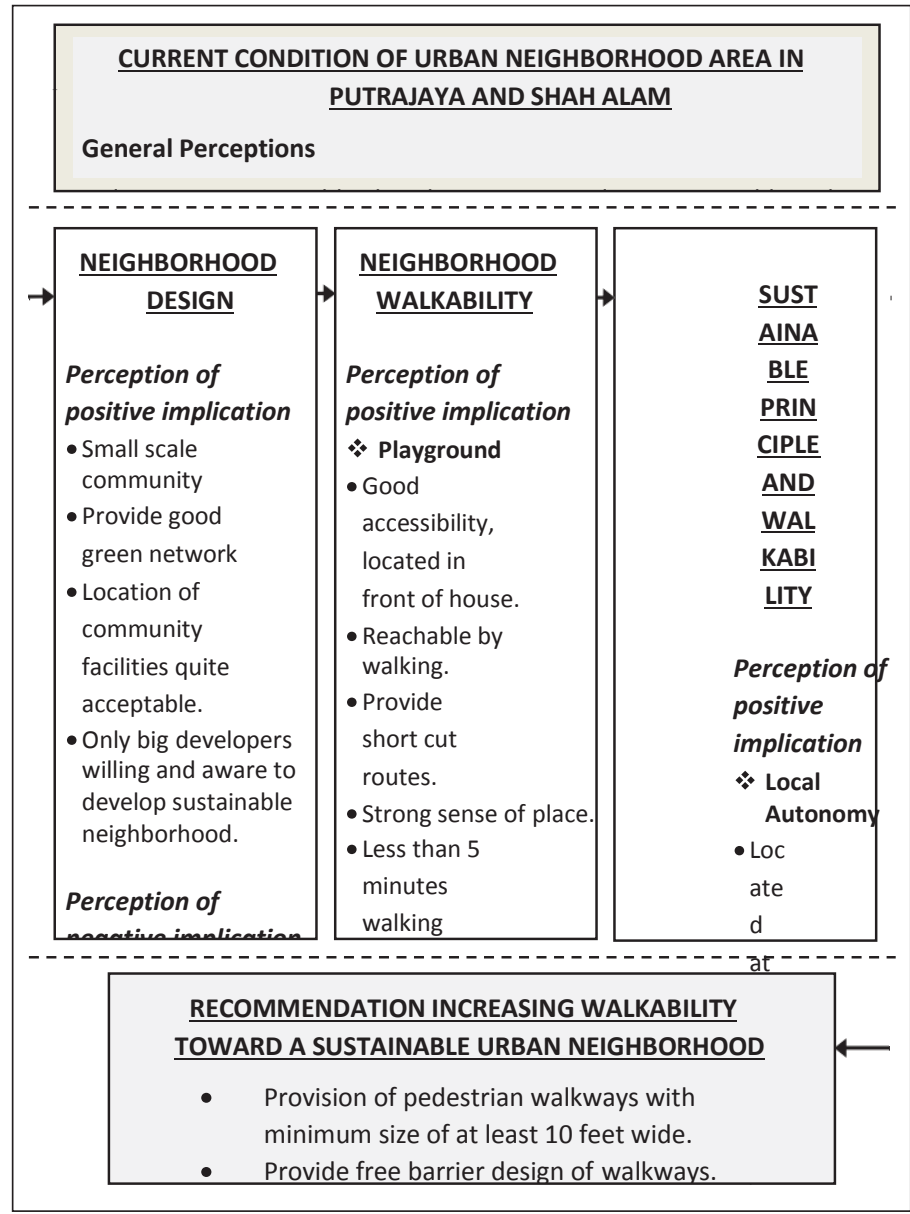

Figure 1: Summary of Qualitative Findings on Perceptions for Implication of Walkability and Sustainability Principle at Urban Neighborhood Area in Putrajaya and Shah Alam. Adapted from, Karim, 2008

For perceptions on the convenience, the respondents think that the pedestrian walkways and cycling path provided in an urbanneighborhood area in Putrajaya and Shah Alam are too narrow. The pedestrian walkways are also not well connected and lack of covered paths. In a 
tropical climate such as Malaysia, this is why Malaysian are not willing to walk because the condition of pedestrian walkways is not comfortable nor pleasant. Urban neighborhoods in Putrajaya and Shah Alam also lack handicap facilities, tend to make this group of people unable to use the community facilities provided. In terms of landscape planning, the respondents view that neighborhood area in Putrajaya and Shah Alam lack of signage for walking people and big shady trees. From the respondents' perception, hot climate also is the main reason that discourages people to walk, thus reducing walkability in an urban neighborhood.

\subsection{Conclusion}

This paper can conclude that urban neighborhood design in Putrajaya and Shah Alam are still lack in encouraging people to walk. Other than that, certain community facilities that provided in an urban neighborhood areas are not provided at strategic locations. The sustainable principle can be adapted in designing a neighborhood to improve the walkability of people in the urban neighborhood area.

\subsection{Recommendation}

From the interview, respondents are able to give their recommendation on theimplication of walkabilitytowards promoting sustainableneighborhood. Findings from the analysis show that neighborhood design in Putrajaya and Shah Alam are still unable to encourage people to walk within the neighborhood. The recommendations put by the expertise to increase walking convenient to provide wider pedestrian walkways with the width of 10 feet. Free barrier walkways with more shade element should be provide in the neighborhood area to encourage people to walk. Moreover, community facilities within neighborhoods should be clustered at the center so it can give comfort and easy for walking people. Other than that, the beautiful green network that is provided especially in Putrajaya should be fully utilize with good connectivity between community facilities and residentialarea. Green elements should also be considered in designing neighborhoods area towards sustainability.

\section{Acknowledgements}

The writers would like to acknowledge the support given by Universiti Teknologi MARA (UiTM), Malaysia Institute of Planners (MIP) and Federal Department of Town and Country Planning Peninsular Malaysia (JPBD Semenanjung Malaysia) during the carrying out of this research.

\section{References}

Abley, S. (2005). "Walkability Scoping Paper”. Retrieved March 04, 2011.

Azmi, D.I. \& Karim, H.A. (2011). A Comparative Study of Walking Behaviour to Community Facilities in Low-Cost 
Azmi, D.I., \& Abdul Karim, H. / Asian Journal of Environment-Behaviour Studies (ajE-Bs), 3(8) May / Jun 2018 (p.167-175)

and Medium Cost Housing. Procedia-Socialand Behavioral Sciences. Volume 35, 2012, Pages 619-628.

Barton, Grant and Guise (2003). Shaping Neighborhoods: A Guide for Health, Sustainability and Vitality.Spon Press: New York,US.

De Chiara, J. and Koppelman, L. (1929). Urban Planning and Design Criteria. New York: Litton Von Nostrand Reinhold Company.

Frank, et al. (2006). "Many Pathways from Land Use to Health". Retrieved March 06, 2011 from Journal of the American PlanningAssociation.

Ghazali et al (2011), Tessellation planning and the small neighborhoodas an appropriate scale for social amenities and engineering infrastructure to meet urban needs. Retrieved April 05, 2011 from 13th International Conference On Humane Habitat(ICHH), Mumbai, India, 28-30 January 2011.

Laforest (2009). Guide to Organizing Semi-Structured Interviews With Key Informant. Québec, Institutnational de santé publique du Québec.

McNally,K(2010).Design GuidelinesforWalkableCommunities. Niehoff Studio.

Neal, Peter (2003). An Urban Village Primer in Urban Vilages and the Making of Communities edited by Peter Neal. London: Spon Press.

Yahyalbrahim(1995).Pembandaran danKejiranan,KualaLumpur:Dewan Bahasa dan Pustaka.

Olson. J (2010). The Neighborhood Unit: How Does Perry's Concept Apply to Modern Day Planning. Texas: EVstudio Colorado \& Texas Architects \& Engineers.

Perry, C. (1910). Housing for the Machine Age. United States.

Ratcliffe,J(1975).An IntroductiontoTownandCountryPlanning.London: Hutchinson \& Company Limited.

Qureshi, S \& Ho Chin Siong, H.C. (2011). Towards Putrajaya Green City 2025 Implementing Neighborhood Walkability In Putrajaya. Retrieved April 05, 2012 from 14th. International Asian Planning Schools Association Congress (APSA 2011).

United Nation Document. From A/42/427. OurCommon Future: Report of the World Commission on Environment and Development. 